\title{
Preparation and Properties of Nano-sized Calcium Fluoride for Dental Applications
}

\author{
Limin Sun and Laurence C. Chow \\ American Dental Association Foundation Paffenbarger Research Center, Polymers Division, \\ National Institute of Standards and Technology, Gaithersburg, MD 20899-8546, USA
}

\section{Abstract}

Objectives-The aim of the present study was to prepare nano-sized calcium fluoride $\left(\mathrm{CaF}_{2}\right)$ that could be used as a labile $\mathrm{F}$ reservoir for more effective $\mathrm{F}$ regimens and as an agent for use in the reduction of dentin permeability.

Methods-Nano-sized $\mathrm{CaF}_{2}$ powders were prepared using a spray-drying system with a two-liquid nozzle. The properties of the nano $\mathrm{CaF}_{2}$ were studied and the effectiveness of a fluoride $(\mathrm{F})$ rinse with nano $\mathrm{CaF}_{2}$ as the $\mathrm{F}$ source was evaluated. The thermodynamic solubility product of the nano $\mathrm{CaF}_{2}$ solution was determined by equilibrating the nano sample in solutions presaturated with respect to macro $\mathrm{CaF}_{2}$. Reactivity of the nano $\mathrm{CaF}_{2}$ was assessed by its reaction with dicalcium phosphate dehydrate (DCPD). $\mathrm{F}$ deposition by $13.2 \mathrm{mmol} / \mathrm{L} \mathrm{F}$ rinse with the nano $\mathrm{CaF}_{2}$ as the $\mathrm{F}$ source was determined using a previously published in vitro model.

Results-X-ray diffraction (XRD) analysis showed pattern of low crystalline $\mathrm{CaF}_{2}$. $\mathrm{BET}$ measurements showed that the nano $\mathrm{CaF}_{2}$ had a surface area of $46.3 \mathrm{~m}^{2} / \mathrm{g}$, corresponding to a particle size of $41 \mathrm{~nm}$. Transmission Electron Microscopy (TEM) examinations indicated that the nano $\mathrm{CaF}_{2}$ contained clusters comprising particles of (10 to 15) nm in size. The nano $\mathrm{CaF}_{2}$ displayed much higher solubility and reactivity than its macro counterpart. $\mathrm{The} \mathrm{CaF}_{2}$ ion activity product (IAP) of the solution in equilibrium with the nano $\mathrm{CaF}_{2}$ was $(1.52 \pm 0.05) \times 10^{-10}$, which was nearly four times greater than the Ksp $\left(3.9 \times 10^{-11}\right)$ for $\mathrm{CaF}_{2}$. The reaction of $\mathrm{DCPD}$ with nano $\mathrm{CaF}_{2}$ resulted in more F-containing apatitic materials compared to the reaction with macro $\mathrm{CaF}_{2}$. The $\mathrm{F}$ deposition by the nano $\mathrm{CaF}_{2}$ rinse was $(2.2 \pm 0.3) \mu \mathrm{g} / \mathrm{cm}^{2}(\mathrm{n}=5)$, which was significantly $(\mathrm{p}<0.001)$ greater than that $\left((0.31 \pm 0.06) \mu \mathrm{g} / \mathrm{cm}^{2}\right)$ produced by the $\mathrm{NaF}$ solution.

Significance-The nano $\mathrm{CaF}_{2}$ can be used as an effective anticaries agent in increasing the labile F concentration in oral fluid and thus enhance the tooth remineralization. It can also be very useful in the treatment for the reduction of dentin permeability.

\section{Keywords}

calcium fluoride; nanoparticle; spray drying; solubility; reactivity; anitcaries; labile F; F regimen; tooth remineralization; dentin permeability

Corresponding author: Limin Sun, 100 Bureau Drive, Stop 8546, ADAF Paffenbarger Research Center, National Institute of Standards and Technology, Gaithersburg, MD 20899-8546, USA, Ph: (301) 975-5379, Fax: (301) 963-9143, Email: limin.sun@ nist.gov.

Publisher's Disclaimer: This is a PDF file of an unedited manuscript that has been accepted for publication. As a service to our customers we are providing this early version of the manuscript. The manuscript will undergo copyediting, typesetting, and review of the resulting proof before it is published in its final citable form. Please note that during the production process errors may be discovered which could affect the content, and all legal disclaimers that apply to the journal pertain.

Disclaimer Certain commercial equipment, instruments, or materials are identified in this paper to specify the experimental procedure adequately. Such identification is not intended to imply recommendation or endorsement by the National Institute of Standards and Technology or the American Dental Association Foundation, nor is it intended to imply that the materials or equipment identified are necessarily the best available for the purpose. 


\section{Introduction}

Calcium fluoride $\left(\mathrm{CaF}_{2}\right)$ and " $\mathrm{CaF}_{2}$-like" materials are of significant interest in dentistry due to their roles as labile fluoride $(\mathrm{F})$ reservoirs in caries prevention. Low concentration of $\mathrm{F}$ in oral fluids derived from labile $\mathrm{F}$ reservoirs formed by the use of $\mathrm{F}$ dentifrices and rinses, have been shown to have a profound effect on the progression of dental caries [1-3]. However, the low calcium (Ca) concentration in the mouth provides a limited driving force for the $\mathrm{CaF}_{2}$ formation, and only very small amounts of $\mathrm{CaF}_{2}$-like deposits are formed after a conventional sodium fluoride $(\mathrm{NaF})$ rinse [4]. Previous studies showed that a two-solution delivery system, which supplies both $\mathrm{F}$ and $\mathrm{Ca}$ in a way that leads to homogeneous nucleation and formation of very small $\mathrm{CaF}_{2}$ crystals in the mouth during application, was highly effective in increasing deposition and retention of labile $\mathrm{F}$ in the mouth [5-6]. This, in turn, increased the remineralization effects of the $\mathrm{F}$ regimen without increasing the $\mathrm{F}$ levels [7-8]. We report here preparation of nano forms of $\mathrm{CaF}_{2}$ which are smaller in size than the $\mathrm{CaF}_{2}$ formed by the twosolution $\mathrm{F}$ rinses. The prepared $\mathrm{CaF}_{2}$ is expected to have high reactivity and could function as labile $\mathrm{F}$ reservoirs when supplied to the mouth through $\mathrm{F}$ dentifrices or rinses.

As previously reported [9], a spray drying process employing very dilute solutions and fine droplets produced nano-sized hydroxyapatite (HA) particles with higher solubility and reactivity than its crystalline macro counterpart. The advantage of this technique over conventional solution precipitation methods is that the nano particles, once formed, are not subject to further washing, and therefore can maintain the high surface reactivity innate to the nano-sized particles. Previously, the nano HA powders were prepared by spraying an acidic calcium phosphate $(\mathrm{Ca} / \mathrm{P}=1.67)$ solution, prepared by dissolving $\mathrm{HA}$ in a volatile acid, through a typical one-liquid nozzle. This method, however, is not feasible for preparing nano particles of relatively insoluble salts, such as $\mathrm{CaF}_{2}$. Availability of two-liquid nozzles makes it possible to prepare nano particles of these salts by the spray drying technique. The cationic and anionic components of the salt are initially present in two separate solutions, which are combined at the time of atomization.

The present study was aimed at preparing nano-sized $\mathrm{CaF}_{2}$ that could be used as a labile $\mathrm{F}$ reservoir for developing potentially more effective $\mathrm{F}$ regimens and as an agent for use in the reduction of dentin permeability. The hypotheses to be tested are (1) spray drying with twoliquid nozzle can produce nano-sized $\mathrm{CaF}_{2}$ with high purity; (2) the solubility and reactivity of nano $\mathrm{CaF}_{2}$ are significantly greater than those of their macro counterpart; (3) a nano $\mathrm{CaF}_{2}$ containing rinse will produce a greater $\mathrm{F}$ deposition than a sodium fluoride $(\mathrm{NaF})$ rinse of the same F content in a previously reported in vitro model [10].

\section{Materials and Methods}

\subsection{Preparation of nano $\mathrm{CaF}_{2}$ powders}

The nano $\mathrm{CaF}_{2}$ powders were prepared using a spray drying system (Fig.1) described previously [9]. A two-liquid nozzle (ViscoMist, Lechler Inc., St. Charles, IL) was employed to allow two solutions to be mixed at the time of atomization. In this study, a calcium solution and a fluoride solution (Table 1), prepared using reagent grade chemicals, were simultaneously fed to the nozzle at a rate of around $10 \mathrm{~mL} / \mathrm{min}$ and atomized into a heated air stream $\left(\approx 70^{\circ}\right.$ C) within a glass column (VM770-48, VM Glass Co., Vineland, NJ, $0.15 \mathrm{~m} \times 0.15 \mathrm{~m} \times 1.22$ $\mathrm{m})$.

The reaction of the $\mathrm{Ca}(\mathrm{OH})_{2}$ and $\mathrm{NH}_{4} \mathrm{~F}$ solutions led to the formation of $\mathrm{CaF}_{2}$ and $\mathrm{NH}_{4} \mathrm{OH}$ (Eq. 1). The nano $\mathrm{CaF}_{2}$ particles suspended in the flow were trapped in the electrostatic precipitator (MistBuster, Air Quality Engineering, Inc., Minneapolis, MN) and collected at the end of the process, while the $\mathrm{NH}_{4} \mathrm{OH}$ was removed as $\mathrm{NH}_{3}$ and $\mathrm{H}_{2} \mathrm{O}$ vapors with the air flow. 


$$
\mathrm{Ca}(\mathrm{OH})_{2}+\mathrm{NH}_{4} \mathrm{~F} \rightarrow \mathrm{CaF}_{2}+\mathrm{NH}_{3} \uparrow+\mathrm{H}_{2} \mathrm{O} \uparrow
$$

\subsection{Microstructural characterization of nano $\mathrm{CaF}_{2}$ powders}

The phase of the obtained nano powders was determined by powder X-ray diffraction (DMAX 2200 XRD, Rigaku Denki, Woodlands, TX). Scans were performed between $10^{\circ}<2 \theta<50^{\circ}$. The estimated standard uncertainty of the $2 \theta$ measurement is $0.01^{\circ}$. The microstructure of the particles was examined using Scanning Electron Microscopy (JSM-5300 SEM, JEOL, Peabody, MA) and Transmission Electron Microscopy (3010 HREM TEM, JEOL). The TEM sample was prepared by depositing particles onto a holey carbon film-coated copper grid from a well-sonicated dilute suspension in acetone to minimize agglomeration. Multipoint BET surface area analyses were done (AUTOSORB-1, Quantachrome Instruments, Boynton Beach, FL) with ultra high purity nitrogen as the adsorbate gas and liquid nitrogen as the cryogen. The samples were dried in air overnight at $110{ }^{\circ} \mathrm{C}$ before the measurement.

\subsection{Solubility measurements}

Although the nano $\mathrm{CaF}_{2}$ was expected to be more soluble than the crystalline $\mathrm{CaF}_{2}$, the solution could precipitate to form crystalline $\mathrm{CaF}_{2}$ during the dissolution process of the nano $\mathrm{CaF}_{2}$, as previously reported for nano hydroxyapatite [9]. Therefore, to improve efficiency and for a direct comparison, the solubility experiments were conducted by dissolving the nano $\mathrm{CaF}_{2}$ in solutions pre-saturated with a highly crystalline $\mathrm{CaF}_{2}$ (reagent grade, Allied Chemical, Morristown, $\mathrm{NJ}$ ), hereafter abbreviated as macro $\mathrm{CaF}_{2}$, as the control. The presaturated solution was prepared by equilibrating the macro $\mathrm{CaF}_{2}$ in a $30 \mathrm{mmol} / \mathrm{L}$ sodium chloride $(\mathrm{NaCl})$ electrolyte background until saturation followed by filtration. The process was repeated three times to diminish the preferential surface adsorption of $\mathrm{Ca}^{2+}$ or $\mathrm{F}^{-}$ions until the $[\mathrm{F}] /[\mathrm{Ca}]$ (quantities in [ ] are concentrations) ratio in the solution was close to their stoichiometric value (i.e., 2). The solubility measurement was conducted at $(21 \pm 1){ }^{\circ} \mathrm{C}$. The solubility of the nano $\mathrm{CaF}_{2}$ was evaluated by adding $33 \mathrm{mg}$ of nano $\mathrm{CaF}_{2}$ into $30 \mathrm{~mL}$ of the presaturated solution under constant stirring (31.4 rad/s or $300 \mathrm{rpm})$. Specific ion electrodes for $\mathrm{Ca}$ and $\mathrm{F}$ and a combination $\mathrm{pH}$ electrode (all from Thermo Electron Co., Woburn, MA) monitored the changes in $[\mathrm{Ca}]$ and $[\mathrm{F}]$ concentrations and $\mathrm{pH}$. The $\mathrm{Ca}$ and $\mathrm{F}$ electrodes were respectively calibrated using a calibration curve that formed by $[\mathrm{Ca}]((0.05,0.1,0.5$ and 1$) \mathrm{mmol} / \mathrm{L})$ or $[\mathrm{F}]$ $((0.1,0.5,1$ and 5$) \mathrm{mmol} / \mathrm{L})$ standards prepared with the same electrolyte background (i.e., 30 $\mathrm{mmol} / \mathrm{L} \mathrm{NaCl})$ from concentrated standard solution $([\mathrm{Ca}]$ or $[\mathrm{F}]$ concentration is $(0.1000 \pm$ 0.0005 ) mol/L) (ThermoOrion, Beverly, MA). The obtained $\mathrm{pH},[\mathrm{Ca}]$, and $[\mathrm{F}]$ values were used to calculate solution ion activity products (IAP) with respect to $\mathrm{CaF}_{2}$ using a commercially obtained software 'Chemist' (Micromath, Saint Louis, MO).

$$
\operatorname{IAP}\left(\mathrm{CaF}_{2}\right)=\left(\mathrm{Ca}^{2+}\right)\left(\mathrm{F}^{-}\right)^{2}
$$

where quantities in ( ) on the right hand side of equation denote ion activities. Both the maximum $[\mathrm{Ca}]$ and $[\mathrm{F}]$ and the calculated IAP values would indicate how much the nano material is more soluble than the control. Three solubility measurements were conducted to establish standard deviation, which was taken as the standard uncertainty.

\subsection{Reactivity of nano $\mathrm{CaF}_{2}$ with dicalcium phosphate dihydrate (DCPD, $\mathrm{CaHPO}_{4} \cdot \mathbf{2 H}_{2} \mathrm{O}$ )}

Mixtures of the nano $\mathrm{CaF}_{2}$ and a ground DCPD (median size $1.6 \mu \mathrm{m}$ ) [11] with a mass ratio of 3:2 were well mixed with distilled water $(\mathrm{P} / \mathrm{L}=1.25)$ into a cement-like paste. The paste was placed into a stainless steel mold with a small hole sandwiched between two porous glass plates and then immersed in $30 \mathrm{ml}$ of a physiological-like solution $(1.15 \mathrm{mmol} / \mathrm{L} \mathrm{Ca}, 1.2 \mathrm{mmol} /$ $\mathrm{L}$ P, $133 \mathrm{mmol} / \mathrm{L} \mathrm{NaCl}, 50 \mathrm{mmol} / \mathrm{L}$ hepes, $\mathrm{pH}$ adjusted to 7.4 by adding $\mathrm{NaOH}$ ) at $37^{\circ} \mathrm{C}$. The 
phase changes of the materials were determined by XRD after $24 \mathrm{~h}$. Another sample prepared with the macro $\mathrm{CaF}_{2}$ and the same DCPD was used for comparison.

\subsection{Evaluation of $\mathrm{F}$ deposition by nano $\mathrm{CaF}_{2}$ using a filter paper model}

Uptake of nano $\mathrm{CaF}_{2}$ particles was tested in an in vitro model [10] using filter discs as the substrate. This method has been shown in a previous study [10] to be a satisfactory model for studying $\mathrm{F}$ deposition on sound enamel from F rinses. Hydrophilic membrane filter discs (Millipore, Bedford, MA) with a pore sizes $0.2 \mu \mathrm{m}$ and a relatively constant thickness (150 $\mu \mathrm{m})$ and pore volume (75\%) was used. Five discs were immersed in $20 \mathrm{~mL}$ of a nano $\mathrm{CaF}_{2-}$ water suspension or a $\mathrm{NaF}$ solution (stirring at $31.4 \mathrm{rad} / \mathrm{s}$ or $300 \mathrm{rpm}$ ) for $1 \mathrm{~min}$. The total $\mathrm{F}$ content was $250 \mu \mathrm{g} / \mathrm{mL}$ in either case. After F exposure, the group of 5 filter discs was rinsed twice in $50 \mathrm{~mL}$ of a solution saturated with respect to $\mathrm{CaF}_{2}$ (stirred at $31.4 \mathrm{rad} / \mathrm{s}$ ) for $15 \mathrm{~s}$ to remove particles that were not firmly attached on/in the disc. Firmly fixed $\mathrm{CaF}_{2}$ particles would not be lost to the washing solution by dissolution because the solution was saturated with respect to $\mathrm{CaF}_{2}$. The $\mathrm{F}$ content in each disc was then determined by a $\mathrm{F}$ ion selective electrode method [12].

\section{Results}

XRD analysis (Fig. 2) showed the obtained powders to be $\mathrm{CaF}_{2}$. The result supported the feasibility of preparing nano particles of highly insoluble compounds using the two-liquid nozzle approach. Compared to its highly crystalline counterpart, the peaks of the nano $\mathrm{CaF}_{2}$ were much broader, indicating a finer crystal size or a more amorphous structure. SEM examinations (Fig. 3a) indicated that particles ranged from $<50 \mathrm{~nm}$ to about $500 \mathrm{~nm}$ in size. The larger particles exhibited numerous spherical protuberances on the surfaces, suggesting that they were formed during the spray drying process through fusion of the much smaller particles. TEM confirmed that the nano $\mathrm{CaF}_{2}$ contained clusters comprised of still finer particles of (10 to 15) $\mathrm{nm}$ in size (Fig. 3b). BET measurements of the nano $\mathrm{CaF}_{2}$ gave a surface area of $46.3 \mathrm{~m}^{2} / \mathrm{g}$. This corresponded to a particle size of $41 \mathrm{~nm}$ assuming a density of $3.18 \mathrm{~g} /$ $\mathrm{cm}^{3}$ and a spherical particle shape for the nano $\mathrm{CaF}_{2}$.

The solubility measurement results (presented as average value \pm standard deviation, Fig. 4) showed that both the $[\mathrm{Ca}]$ and $[\mathrm{F}]$ increased rapidly after the addition of the nano $\mathrm{CaF}_{2}$, which leveled off after (10 to 15) min. Only very slight changes occurred with the addition of the macro $\mathrm{CaF}_{2}$ as expected, and the small changes could be attributed to the preferential surface adsorption of $\mathrm{Ca}^{2+}$ or $\mathrm{F}^{-}$ions as mentioned before. This indicated that the nano $\mathrm{CaF}_{2}$ was significantly more soluble than macro $\mathrm{CaF}_{2}$. The $\mathrm{pH}$ dropped significantly in both cases from the initial value of 6.2 to about 5.0 and 4.3 for the nano $\mathrm{CaF}_{2}$ and macro $\mathrm{CaF}_{2}$, respectively. The $\mathrm{pH}$ rebounded slightly after the initial drop in the case of the nano $\mathrm{CaF}_{2}$. The reason for the $\mathrm{pH}$ drop was not clear. The calculated pIAP $\left(\mathrm{CaF}_{2}\right)=-\log \left(\mathrm{pIAP}\left(\mathrm{CaF}_{2}\right)\right)$ (Eq. 2) value was

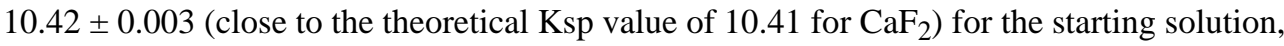
which became $9.82 \pm 0.01$ after 30 min following the addition of the nano $\mathrm{CaF}_{2}$. This corresponded to a calculated IAP value of $(1.52 \pm 0.05) \times 10^{-10}$, which was nearly four times greater than the Ksp of value of $3.9 \times 10^{-11}$ for the $\mathrm{CaF}_{2}$.

In the chemical reaction of $\mathrm{CaF}_{2}$ with DCPD, the XRD patterns (Fig. 5) of the mixtures $24 \mathrm{~h}$ after preparation $(0 \mathrm{~h}$ refers to the mixture of the two powders without water) showed that there was no reduction in the height of peaks for the macro $\mathrm{CaF}_{2}$ whereas the nano $\mathrm{CaF}_{2}$ peaks had some reduction because of being partially consumed by reacting with the DCPD. The DCPD was almost completely consumed in either mixture forming an apatitic product. The conversion from DCPD to apatite was more complete with the nano $\mathrm{CaF}_{2}$ than with the macro $\mathrm{CaF}_{2}$ (by comparing the peaks of DCPD and apatite, Fig. 5). These results showed that the nano $\mathrm{CaF}_{2}$ was more reactive than the macro $\mathrm{CaF}_{2}$ probably because its apparent solubility was greater. 
The fact that nano $\mathrm{CaF}_{2}$ was only partially consumed indicated that it was still less reactive than the DCPD, suggesting that it would be necessary to use still smaller nano $\mathrm{CaF}_{2}$ particles in order to have the $\mathrm{CaF}_{2}$ dissolve in time for the reaction.

The results from the $\mathrm{F}$ deposition model showed that a $\mathrm{F}$ rinse comprising nano $\mathrm{CaF}_{2}$ produced $\mathrm{a} \approx 7$ times $(\mathrm{p}<0.01)$ greater $\mathrm{F}$ deposition $\left((2.20 \pm 0.45) \mu \mathrm{g} / \mathrm{cm}^{2}, \mathrm{n}=5\right)$ than that $((0.31 \pm 0.06)$ $\mu \mathrm{g} / \mathrm{cm}^{2}$ ) by a conventional $\mathrm{NaF}$ rinse having the same $\mathrm{F}$ content of $13.2 \mathrm{mmol} / \mathrm{L}$.

\section{Discussion}

A potential disadvantage of the two-liquid nozzle spray drying technique is that the chemical reaction between the two reactants and therefore the composition of the nano product depend directly on the relative feeding rates and mixing efficiency of the two liquids. In the present case, an excess feeding rate of the $\mathrm{Ca}(\mathrm{OH})_{2}$ solution or the $\mathrm{NH}_{4} \mathrm{~F}$ solution would lead to the formation of $\mathrm{Ca}(\mathrm{OH})_{2}$ or $\mathrm{NH}_{4} \mathrm{~F}$, respectively, as an impurity component in the product. The XRD pattern (Fig. 3), showed no traces of either $\mathrm{Ca}(\mathrm{OH})_{2}$ or $\mathrm{NH}_{4} \mathrm{H}$, indicating that the obtained nano $\mathrm{CaF}_{2}$ powders were pure. This implied that stoichiometric amounts of the two reactants were fed to the spray nozzle and that they were well mixed and completely reacted at the time of atomization. The calculated d values for the crystal planes (111) and (220) were respectively $1.933 \mathrm{~nm}$ and $3.155 \mathrm{~nm}$, which were close to the standard values: $1.931 \mathrm{~nm}$ for (111) and 3.153 $\mathrm{nm}$ for (220), respectively [13]. The broader peaks in the nano $\mathrm{CaF}_{2}$ pattern indicated a fine crystallite size, which was around $15 \mathrm{~nm}$ based on calculations using Scherrer's formula [14]. This is in agreement with the observation that the sub-particles that composed the primary nano $\mathrm{CaF}_{2}$ particles as revealed by TEM were about $15 \mathrm{~nm}$ in size (Fig. 3b). It is speculated that better dispersed individual particles could be produced by using more dilute solutions, a lower spraying rate or larger reaction chamber. Preliminary results showed that addition of a surfactant to the reactant solutions noticeably increased the surface area of the nano $\mathrm{CaF}_{2}$ obtained, suggesting that the surfactant also helped disperse the particles better. The XRD peak broadening could also be related to a less ordered lattice structure as a result of the rapid chemical reaction during spray drying. Both of these two factors (nano-size, i.e., larger surface area, and disordered lattice) could contribute to higher solubility observed for the nano $\mathrm{CaF}_{2}$ reported above.

One of the most important properties of calcium phosphate/calcium fluoride materials is their solubility behavior because most reactions of these compounds in the aqueous environment are driven by relative solubility/reactivity of the reactant and product. Due to its higher solubility, a greater amount of the nano $\mathrm{CaF}_{2}$ was consumed by its reaction with DCPD compared to the macro $\mathrm{CaF}_{2}$ (Fig. 5), which should lead to a greater amount of $\mathrm{F}$ incorporation in the apatitic product formed. This suggests that the nano $\mathrm{CaF}_{2}$ could be a good agent for use in the reduction of dentin permeability. Dentin hypersensitivity has been associated with permeable dentin resulting from exposed dentin tubules [15]. Treatments that can produce massive amounts of mineral precipitates within dentin tubules are potentially useful for desensitization treatment [16]. However, since the tubule openings are small $(<5 \mu \mathrm{m}$ in diameter) and are often partially covered by a "smear layer" [15], obturation of the tubule could not be easily accomplished. The nano $\mathrm{CaF}_{2}$ can be used as slurry for the treatment since the nano particles can penetrate into the tubules. But the treatment would be more effective when the nano $\mathrm{CaF}_{2}$ is combined with calcium phosphate, which can produce more F-containing apatitic products that would be more stable in the mouth under both normal and cariogenic conditions [17-18] than the calcium phosphate only treatment [16].

Previous studies [10] have shown a good correlation between the $\mathrm{F}$ deposition on the filter disc substrate and that on sound enamel. The $\mathrm{F}$ deposition by the $\mathrm{CaF}_{2}$ rinse using nano $\mathrm{CaF}_{2}$ as the fluoride source in the current study produced about a seven times greater $\mathrm{F}$ deposition than 
the conventional $\mathrm{NaF}$ rinse $\left((2.20 \pm 0.45) \mu \mathrm{g} / \mathrm{cm}^{2}\right.$ for nano $\mathrm{CaF}_{2}$ rinse vs. $(0.31 \pm 0.06) \mu \mathrm{g} /$ $\mathrm{cm}^{2}$ for $\mathrm{NaF}$ rinse) when the same $\mathrm{F}$ concentration was used. This suggests the possibility that the nano $\mathrm{CaF}_{2}$ would have a high affinity to oral substrates and therefore would be more effectively retained in the mouth, serving as a longer lasting source for ambient $F$ than that produced by currently used $\mathrm{NaF}$ products. Results of a pilot in vivo study showed that a 1-min application of this nano $\mathrm{CaF}_{2}$ rinse produced a significantly $(\mathrm{p}<0.05)$ greater 1-h post rinse salivary $\mathrm{F}$ content $(158 \mu \mathrm{mol} / / \mathrm{L})$ than that $(36 \mu \mathrm{mol} / \mathrm{L})$ produced by the $\mathrm{NaF}$ rinse. It is expected that a better dispersed nano $\mathrm{CaF}_{2}$ powder (larger surface area) could produce an even higher $\mathrm{F}$ deposition based on our preliminary results with the nano $\mathrm{CaF}_{2}$ sprayed with surfactant, which will be further studied in the future. The in vitro F deposition results $((2.20 \pm 0.45) \mu \mathrm{g} /$ $\mathrm{cm}^{2}$ ) also indicated that the nano $\mathrm{CaF}_{2}$ rinse was about equally effective as a novel two-solution rinse [19] which produced $\mathrm{F}$ deposition of $(2.62 \pm 0.16) \mu \mathrm{g} / \mathrm{cm}^{2}$. However, one component of the two-solution rinse, sodium hexafluorosilicate, $\mathrm{Na}_{2} \mathrm{SiF}_{6}$, was not be acceptable as $\mathrm{F}$ source by the Food and Drug Administration, and also the nano $\mathrm{CaF}_{2}$ rinse would have the advantage of being a single solution rinse rather than a two-solution product.

\section{Acknowledgements}

The authors thank Stanislav A. Frukhtbeyn of ADAF-PRC, Dr. Bernard Hockey of Ceramics Division and Max A. Peltz of Materials and Construction Research Division of NIST for technical assistance. This investigation was supported, in part, by USPHS Research Grants DE 16416 to the American Dental Association Foundation from the National Institutes of Health - National Institute of Dental and Craniofacial Research and is part of the dental research program conducted by the National Institute of Standards and Technology in cooperation with the American Dental Association Foundation.

\section{References}

1. Rølla G. On the role of calcium fluoride in the cariostatic mechanism of fluoride. Acta Odontol Scan 1988;46:341-345.

2. Lagerlof F, Ekstrand J, Rolla G. Effect of fluoride addition on ionized calcium in salivary sediment and in saliva. Scand J Dent Res 1988;96:399-404. [PubMed: 3201111]

3. Rølla G, Saxegard E. Critical evaluation of the composition and use of topical fluorides with emphasis on the role of calcium fluoride in caries inhibition. J Dent Res 1990;69(Spec):780-785. [PubMed: 2179341]

4. Saxegaard E, Rølla G. Kinetics of acquisition and loss of calcium fluoride by enamel in vivo. Caries Res 1989;23:406-411. [PubMed: 2598228]

5. Chow LC, Takagi S. Deposition of fluoride on tooth surfaces by a two-solution mouth Rinse in vitro. Caries Res 1991;25:397-401. [PubMed: 1810650]

6. Vogel GL, Mao Y, Carey CM, Chow LC, Takagi S. In vivo fluoride concentrations measured for two hours after a NaF or a new two-solution rinse. J Dent Res 1992;71:448-452. [PubMed: 1573075]

7. Chow LC, Takagi S, Carey CM, Sieck BA. Remineralization effects of a two-solution fluoride mouthrinse: An in situ study. J Dent Res 2000;79:991-995. [PubMed: 10831103]

8. Chow LC, Takagi S, Frukhtbeyn S, Sieck S, Parry EE, Liao NS, Schumacher GE, Markovic M. Remineralization effect of a low-concentration fluoride rinse in an intraoral model. Caries Res 2002;36:136-141. [PubMed: 12037371]

9. Chow LC, Sun L, Hockey B. Properties of nanostructured hydroxyapatite prepared by spray drying technique. J Res Natl Inst Stand Technol 2004;109:543-551.

10. Takagi S, Liao H, Chow LC. Effect of a low-fluoride-content, two-component rinse on fluoride uptake and on de- and remineralization of enamel lesions: An in vitro study. Caries Res 2001;35:223-228. [PubMed: 11385204]

11. Sun L, Chow LC, Takagi S, Burguera E, Frukhtbeyn SA. Influence of particle size on DCPD hydrolysis and setting properties of TTCP/DCPD cement. Key Eng Mater - Bioceramics 17:284-86. 23-26.

12. Vogel GL, Chow LC, Brown WE. A microanalytical procedure for the determination of calcium, phosphate and fluoride in enamel biopsy samples. Caries Res 1983;17:23-31. [PubMed: 6571804] 
13. Mineral powder diffraction file data book. Swarthmore, PA: International Center for Diffraction Data; 1986.

14. Cullity, BD. Elements of X-ray Diffraction. 2nd. Addition-Wesley Publishing Co.; Reading, MA: 1978. p. 415

15. Brännström, M. A hydrodynamic mechanism in the transmission of pain-producing stimuli through the dentin. In: Anderson, DJ., editor. Sensory Mechanisms in Dentine. 1. London: Pregamon Press; 1963. p. 73-79.

16. Cherng AM, Chow LC, Takagi S. Reduction in dentin permeability ssing mildly supersaturated calcium phosphate solutions. Arch Oral Biology 2004;49:91-98.

17. Wefel JS, Harless JD. Topical fluoride application and lesion progress in vitro. J Dent Res 1984;63:1276-1278. [PubMed: 6594368]

18. White DJ, Nelson DG, Faller RV. Mode of action of fluoride: Application of new techniques and test methods to the examination of the mechanism of action of topical fluoride. Adv Dent Res 1994;8:166174. [PubMed: 7865071]

19. Chow, LC.; Takagi, S. Control of calcium fluoride formation in mouth rinses, dentifrices and gels. US patent 5,891,448. 1999. 

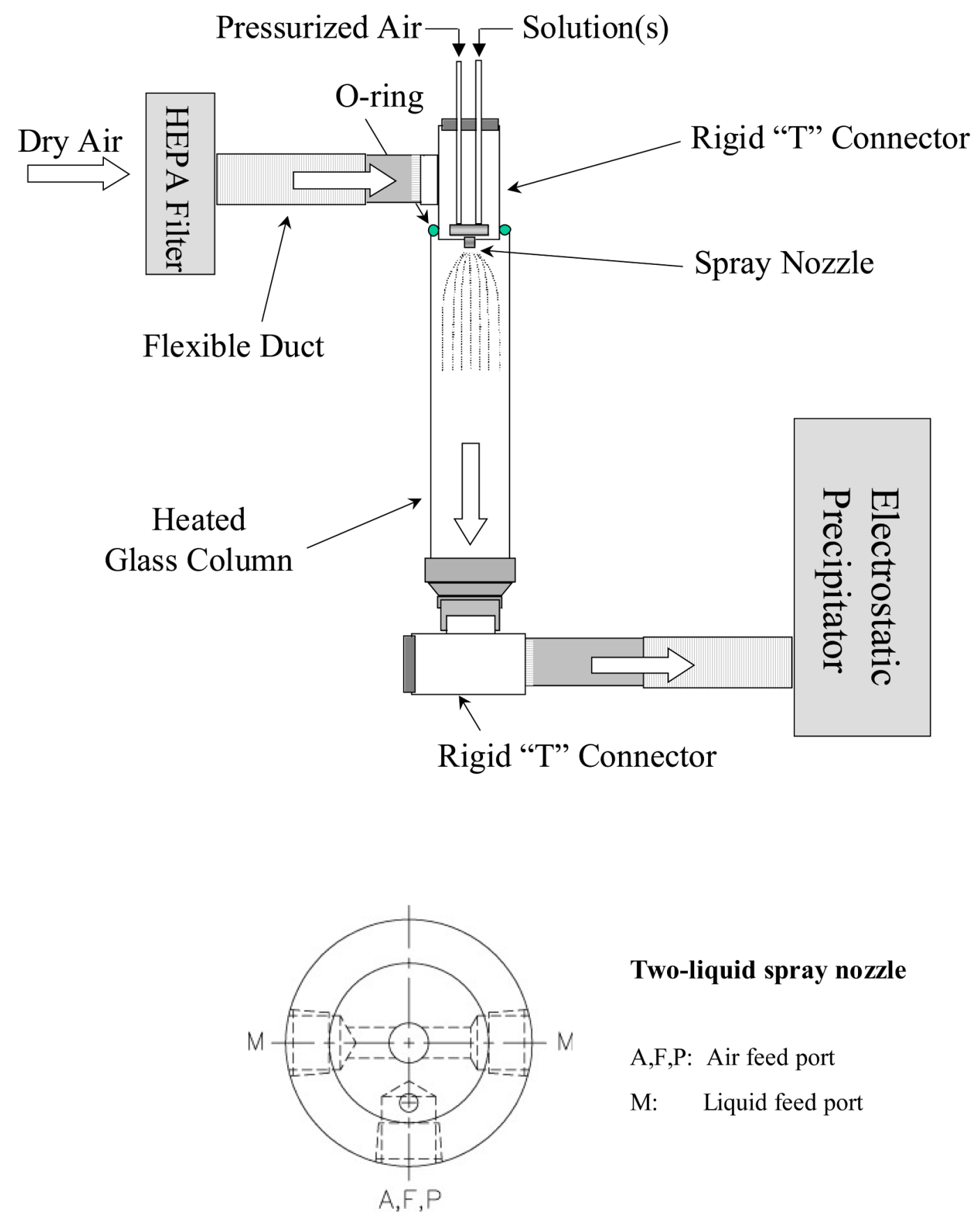

Two-liquid spray nozzle

A,F,P: Air feed port

M: $\quad$ Liquid feed port

Fig. 1.

Schematic drawing of the spray drying apparatus and two-liquid spray nozzle. 


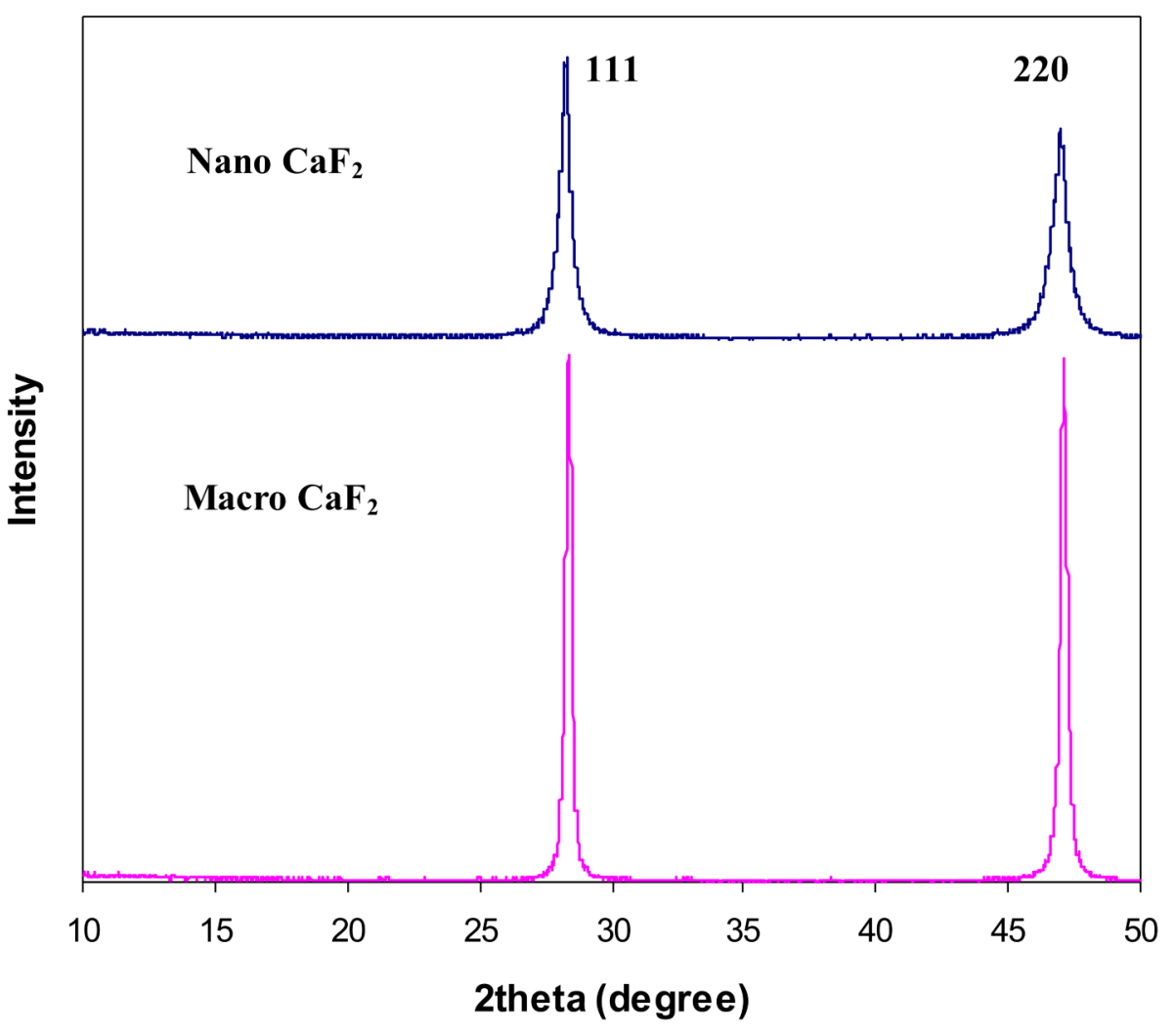

Fig. 2.

XRD patterns showing that the nano $\mathrm{CaF}_{2}$ was of low crystallinity. 

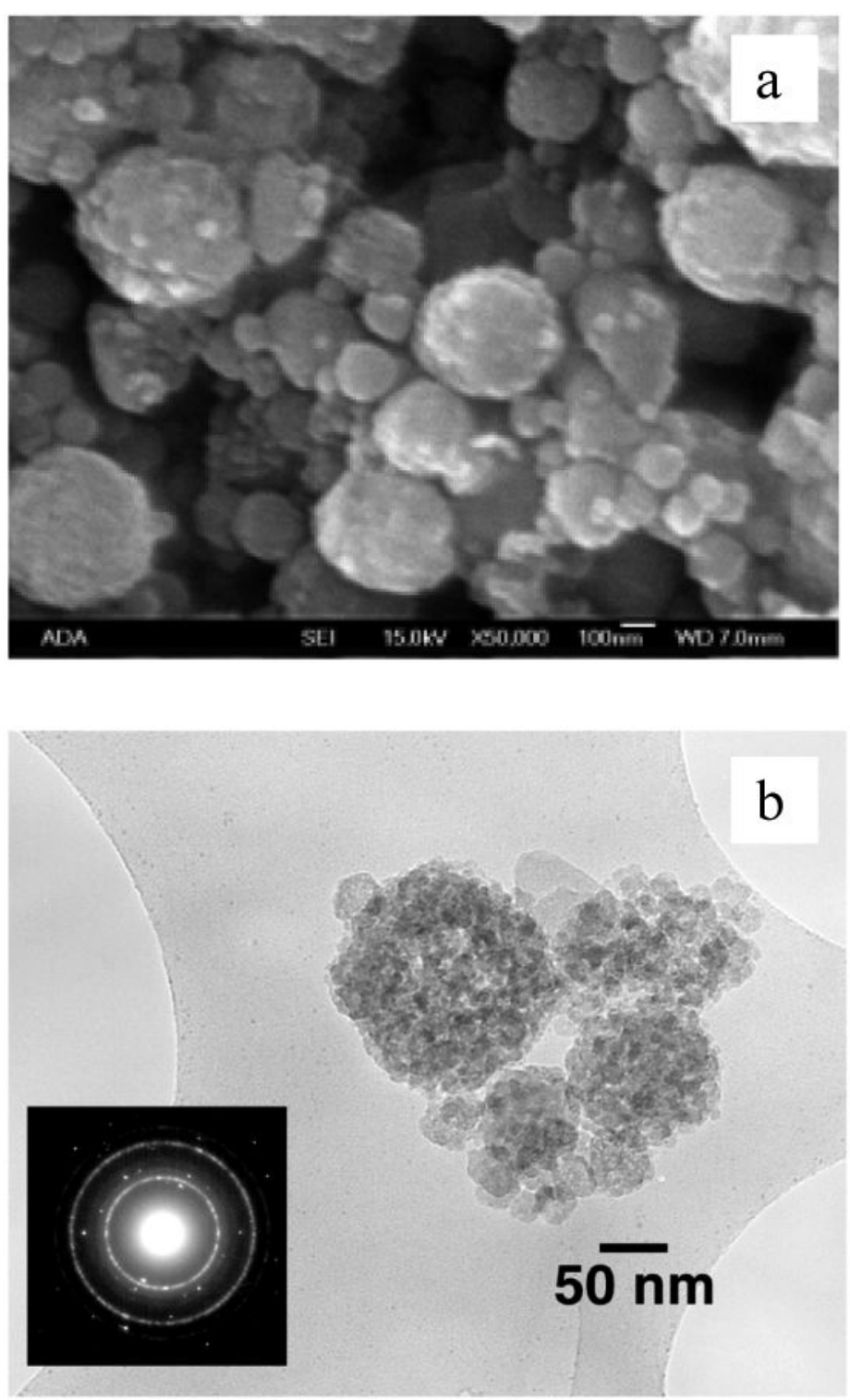

Fig. 3.

SEM (a) and TEM (b) of nano $\mathrm{CaF}_{2}$ showing conglomerates consisting of particles of about (10 to15) $\mathrm{nm}$ in size. 


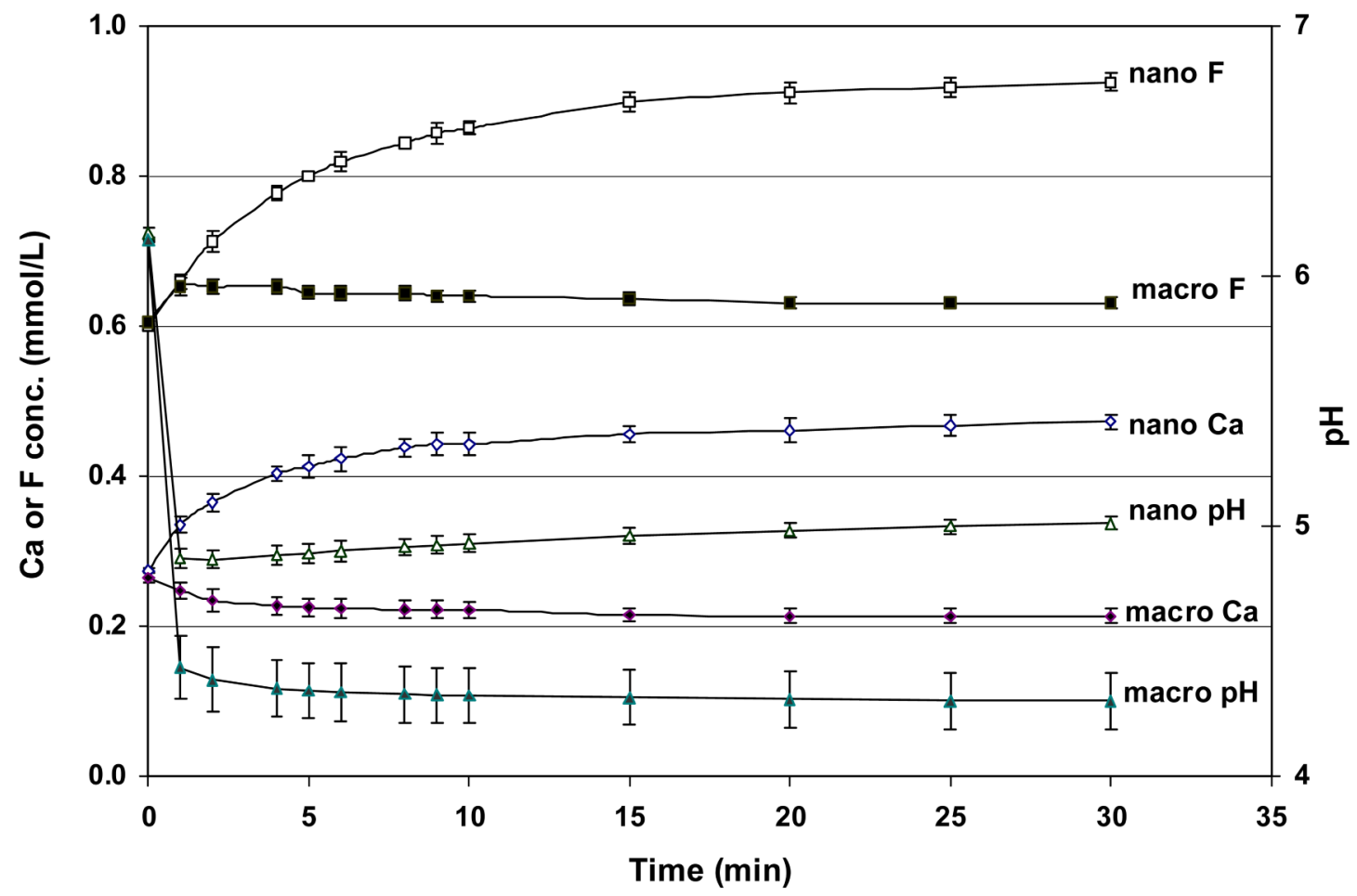

Fig. 4.

Changes in $[\mathrm{Ca}]$ and $[\mathrm{F}]$ concentrations and $\mathrm{pH}$ from dissolution of nano $\mathrm{CaF}_{2}$ in a solutions presaturated to highly crystalline $\mathrm{CaF}_{2}$. 

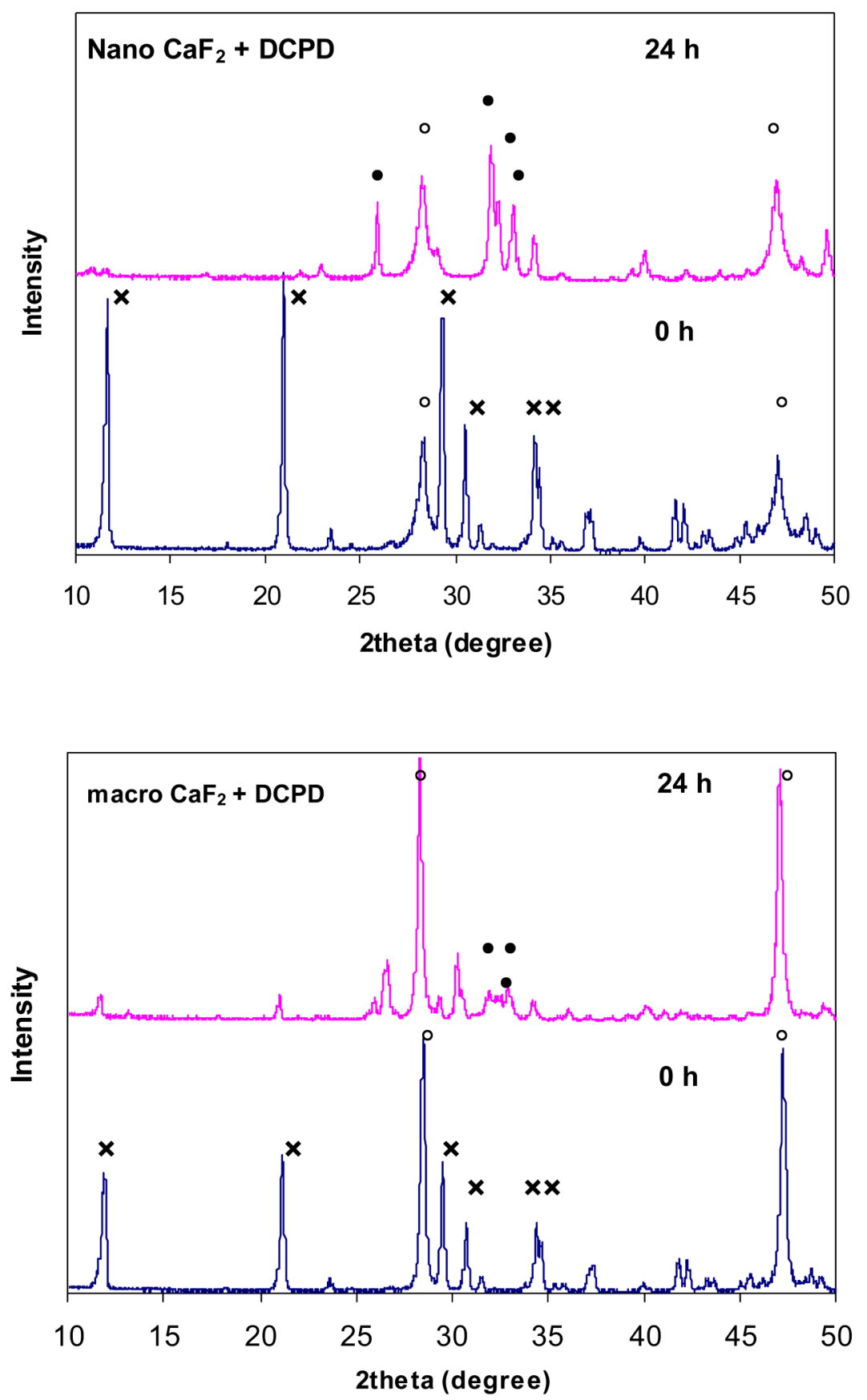

Fig. 5.

XRD patterns showing that a greater amount of nano $\mathrm{CaF}_{2}$ was consumed than was macro $\mathrm{CaF}_{2}$ in reaction with DCPD $\left(\times-\mathrm{DCPD},{ }^{\circ}-\mathrm{CaF}_{2} \cdot-\right.$ apatite $)$. 
Table 1

Compositions of the calcium and fluoride solutions used for preparing nano-sized $\mathrm{CaF}_{2}$

\begin{tabular}{|c|c|c|c|}
\hline Solutions & Chemicals & Formula & Concentrations \\
\hline $\mathrm{Ca}$ & calcium hydroxide & $\mathrm{Ca}(\mathrm{OH})_{2}$ & $2 \mathrm{mmol} / \mathrm{L}$ \\
\hline $\mathrm{F}$ & ammonium fluoride & $\mathrm{NH}_{4} \mathrm{~F}$ & $4 \mathrm{mmol} / \mathrm{L}$ \\
\hline
\end{tabular}

